\title{
INFORMATIVE CONTENT MODELS FOR INFRASTRUCTURE LOAD TESTING MANAGEMENT: THE AZZONE VISCONTI BRIDGE IN LECCO
}

\author{
M. Previtali ${ }^{1,}{ }^{*}$, L. Barazzetti ${ }^{1}$, F. Banfi ${ }^{1}$, F. Roncoroni ${ }^{2}$ \\ ${ }^{1}$ Politecnico di Milano, Department of Architecture, Built Environment and Construction Engineering, \\ Via Ponzio 31, 20133 Milano, Italy - (mattia.previtali, luigi.barazzetti, fabrizio.banfi)@ polimi.it \\ ${ }^{2}$ Politecnico di Milano, Polo territoriale di Lecco, Via Gaetano Previati, 1/c, 23900 Lecco LC - fabio.roncoroni@ polimi.it
}

KEY WORDS: BIM, Bridge, Load testing

\begin{abstract}
:
Informative models are not limited only to new construction or existing building but can also be used (also been used) for large infrastructure management like bridges. The adoption of informative content models for structural health monitoring (SHM) of such infrastructures poses some issues that need to be solved in order to develop smooth management and maintenance workflows. This paper describes a novel methodology for the generation of a detailed BIM of a complex medieval bridge and the possibility to link specific data coming from load testing. Integration of information coming from different data sources is one of the most important aspects for the development of maintenance programs. However, each actor in the process makes use of different strategies and protocols whose integration can generate bottlenecks. To partially overcome this limitation a cloud-based solution was used, and a Building Information Model (BIM) of the bridge was used as main collector of information for the different stakeholders involved in its management.
\end{abstract}

\section{INTRODUCTION}

Large scale infrastructures, and in particular bridges and viaducts, are critical assets since most of them have been built during the last century and in particular after the ' 50 s (Scheer, 2011). Infrastructures were designed taking into consideration an expected life of 50 years, and many of them are very close to the end of the design life, or even beyond. For this reason, the ageing of those infrastructures is now becoming a key challenge, and specific actions need to be taken to evaluate their safety and analyse if a maintenance plan can guarantee an extension of their life (Agdas et al., 2015). Furthermore, some infrastructure has shown faster deterioration process due to design or poor construction, which is accelerated by external factors such as increased traffic loads, climate change and natural and human-made hazards. All this reduces the expected lifetime of more recent infrastructures as well, requiring inspection, monitoring and diagnosis.

For this reason load carrying the capacity assessment of a bridge is a key aspect to properly assess the residual lifetime. Indeed, the possibility that a given bridge may have reserves of strength in excess of the predicted value means that its lifetime, possibly with some retrofitting interventions, can be extended. Roughly speaking a load test involves placing loads of known magnitude on the bridge and measuring displacement and/or strain.

Since different expertise (e.g., operators devoted to displacements/strains measurements, structural engineers that have to evaluate the testing results, own of the infrastructures that have to face strengthening works etc.) are involved in the load testing phase the availability of a unique repository to collect data is of primary importance to provide a single point of access for the different professionals involved. Although this is only a part of the solution, it is clear the importance of tools enabling the development of a holistic approach for monitoring, control, upgrade and maintenance. Building Information Modelling (BIM) has gained much popularity in the last years for the design, construction, operation and maintenance of new constructions (Volk et al. 2014). At the core of building information modelling (BIM), a data model, is used to integrate all relevant information during its lifecycle based on 3D digital technology (Banfi 2016). The possibility to integrate BIM technology and sensing data for bridge and infrastructure management has been tested in Jeong et al. (2017) while Hu et al. (2016) developed an information model based on industry foundation classes to improve interoperability between architectural and structural design models. Lin et al. (2019) also present the integration of BIM and sensor data to enable dynamic comparison and tracking of simulation results and monitoring data for risk assessment. Corongiu et al. (2018) present the integration of data coming from different domains in geo-information management of railway infrastructure. BIM also reveals very useful for structural analysis (Korumaz et al., 2017). Even if a large literature is focusing on BIM of new construction the adoption of the BIM paradigm to existing infrastructure is still problematic. Even if Barazzetti et al. (2016) Demonstrates also the feasibility of the BIM model to model historical bridges, technical, economic and organisational bottlenecks exist for BIM adaptation to the management of existing infrastructures. In this paper, we are presenting a methodology to incorporate load testing information into a BIM project that can partially cope with those barriers. Indeed, several numerical and graphical results can be incorporated into a BIM model: displacements measured during the monitoring stage, GPR (Ground Penetrating Radar) data to inspect internal structures, mapping of cracks, stratigraphy, mechanical characterization, etc. In particular, this paper presents the management of the loading test results of the Ponte Azzone Visconti in Lecco over the Adda River, in Lecco (Italy). In particular, a levelling campaign was carried out to evaluate deformations under the loading phase of the bridge under different load configuration. Vertical displacements can be directly correlated to $3 \mathrm{D}$ information and can be stored in different ways in the BIM, also including links to reports and images.

The remaining of the paper is organized as follows: section 2 presents a short review of relevant works focusing on 
measurements techniques of bridge displacement under loading test and integration of monitoring data with BIM, section 3 introduces the aims of the loading tests of the Azzone Visconti Bridge and briefly summarize its history. Section 4 presents a brief overview of the adopted approach to integrating loading test results in a BIM framework. The displacement measurement technique adopted in outlined in section 5 while a detailed discussion on data integration is the main topic of section 6. The last section presents some conclusions and defines future works.

\section{RELATED WORK}

As previously anticipated during a load test displacement or strains are measured. However, due to the higher difficulty in measuring in an accurate way strains, during displacement are generally monitored during a load test. Some bridge displacement monitoring approaches have been implemented, and the reader is an addressed to Brownjohn et al. (2015) for a complete review of this topic along with a discussion of advantages and disadvantages of each of them. Here just a few of them will be covered and briefly reviewed. The method used for displacement measurements depends on a set of different factors. Among them, we can name: (i) spatial, and temporal resolution (sample rate/frequency) of the measurement; (ii) requested measurement accuracy compared with expected displacements; (iii) stability of fixed reference points; (iv) scheduling of the loading tests. Linear Variable Differential Transformers (LVDT) sensor are generally used for short span bridges over accessible land and when a fixed reference below the bridge is available. However, LVDT can be more difficult to be used in the case of long-span bridges over water. Other measurement techniques can include GPS monitoring. GPS id becoming more and more widespread for bridge displacement measurement. For example, Wong (2007) and presents the GPS monitoring system of the networks of bridges operated by Nanjing's Jiangsu Transportation Institute and Hong Kong Highways Dept. Tang et al. (2017) presents an approach based on real-time kinematic precise point positioning GPS for structure monitoring applied on the Severn Suspension Bridge in the UK. Xi et al. (2018) compared BeiDou and GPS RTK for displacement monitoring of the Baishazhou Yangtze River Bridge in Wuhan, China. However, as discussed by Mochas and Stiros (2014) it is generally challenging to measure relatively stiff footbridge where movement ranges are modest. Robotic total stations (RTS) are frequently used for the measurement of temperature induced bridge deformations or during load testing of bridges (Zhou et al., 2006). The advantage of RTS monitoring, compared with LVDT is the possibility to measure 3D displacement vectors instead of uniaxial vertical displacement. However, to obtain results with sub-millimetre accuracy the design of the acquisition network needs to be carefully planned as well as the repositioning of the instrument. Also, the acquisition time can be quite long slowing down scheduling of the loading tests. Laser tracker systems were also used to monitor bridge displacements during load tests. The advantage of a laser tracker system compared with an RTS is the higher accuracy in range measurement. Another geodetic method for measuring bridge displacements is based on geometric levelling. Geometric levelling is used to measure differences in elevations between two or more points at the Earth's surface. Experience has shown geometric levelling to be a reliable and precise vertical displacement measurement method. Modern electronic levels, with automatic reading and recording, have significantly improved geometric levelling operational performances (Okiemute and Fatai 2018). Some authors (Sekiya et al., 2016; Noel et al., 2017; Hester et al., 2017) focused on the problem of calculating bridge displacement from acceleration. Aside from not knowing exactly the initial conditions (velocity and displacement), the fundamental problem with integrating acceleration to calculate displacement is the amplification of the low-frequency noise that inevitably exists in real acceleration data.

REVIEW BIM-PONTI-SENSORI (BANFI)

\section{CASE STUDY: AZZONE VISCONTI BRIDGE}

The Azzone Visconti Bridge, also known as "Ponte Vecchio" (i.e. "The old bridge") is the oldest bridge crossing the Adda river in Lecco. The bridge is a masonry one and was built between 1336 and 1338 and today is the symbol of the city. During centuries the bridge underwent different changes in its configuration. Originally a portion of the bridge was built as a drawbridge and set of fortified structures protected its access. So the bridge was originally built with eight arches and was later expanded into two steps (1350 and 1434) up to 11 arches. Currently, it consists of ten piers, eleven arches and two bridge abutments, one on the Lecco side and one on the Malgrate side of the Adda river. The Azzone Visconti Bridge has been for centuries (until 1955) the unique road connection between the two banks of Adda river. The construction of the Kennedy bridge (1955) and of the Manzoni bridge (1985) has significantly reduced the vehicle traffic on the Azzone Visconti bridge but it is still an important access road to the town of Lecco. Deterioration of the cantilever steel beams located that constituted the pedestrian platform of the sidewalks leading the Municipality of Lecco at establishing a collaboration with Politecnico di Milano (Polo Territoriale di Lecco) with the aim of investigating the bearing capacity of the bridge.

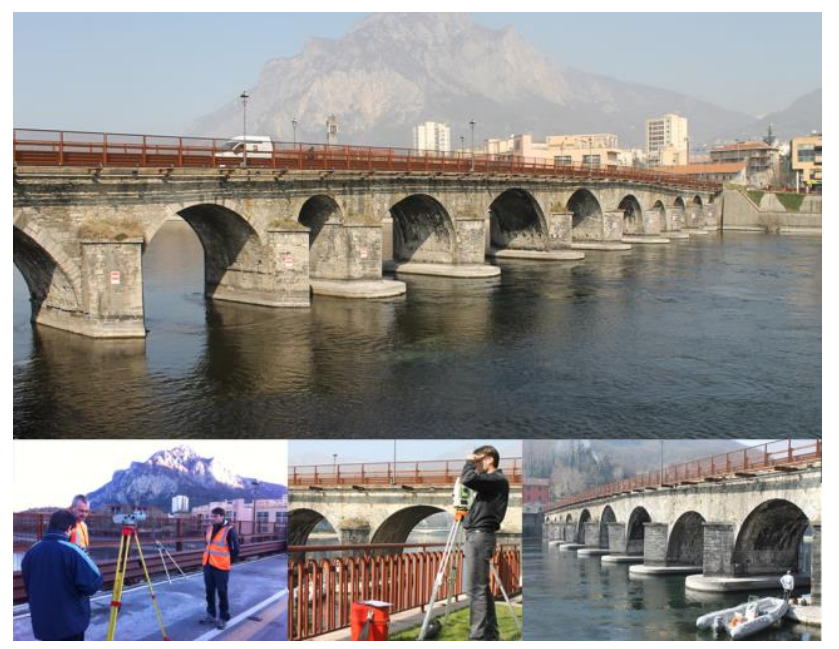

Figure 1. Azzone Visconti bridge and the 3D survey and levelling campaigns

A set of different expertise and research groups were involved in the project to evaluate the state of conservation of the bridge and investigating its bearing capacity.

The load tests were designed looking to the Italian Technical Regulations for Construction for a first-class bridge. In particular, two types of test protocol were executed:

- Type A test: application of about $750 \mathrm{kN}$ by means of two truck mixers on small span arches; and 
- $\quad$ Type B test: application of about $1200 \mathrm{kN}$ by means of truck mixers and steel coils on the longest span arch.

The most severe loading procedure (type B test) was carried out by step-wise positioning two sets of steel coils supported by a suitable steel frame and two four axes truck mixers on the arch.

\section{INTEGRATION STRATEGY OVERVIEW}

As previously anticipated the main aim of this paper is to present the strategy used to integrate results of the testing phase into a BIM framework. An overview of the integration strategy is presented in Figure 1.

The generation of the bridge BIM was carried out using as a primary source of information a geometric survey of the bridge carried out with laser scanning and photogrammetric techniques. Expected accuracies can be evaluated in the order of magnitude of some millimetres in the point cloud registration since a geodetic network was materialized and then measured to constrain the scan alignment (Tucci et al., 2013). The modelling required the definition of some new specific grade of generation to take into consideration the complex shape of the Azzone Bridge.

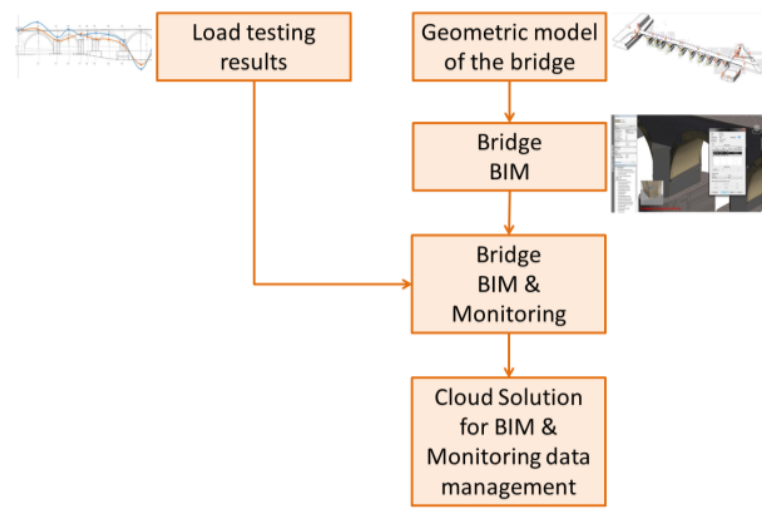

Figure 2. Workflow of the proposed integration approach

During the modelling phase, a set of benchmarks was generated to associate them the measurements carried out during the load testing phase. For the definition of the vertical displacements of the bridge during the test, a levelling network was established to define the displacements of a set of benchmarks connected to the structure. Displacement measurements of benchmarks are then linked to the "virtual benchmarks" created in the BIM model of the bridge. Finally, the resulting informative model is shared with a BIM cloud system.

\section{LOADING TEST: DISPLACEMENT MEASUREMENT}

As discussed in section 2 several strategies exist for displacement measurements during the loading test. Factors that influenced the testing phase are the following:

i. Number of points to be monitored: structural engineers requested to monitor displacements in correspondence of each pier and the middle of each arch in both faces of the bridge;

ii. Nature of the displacements: the interest during tests was mainly on vertical displacements; iii.

Requested accuracy: due to the stiffness of the bridge expected displacements were quite modest (in the majority of the tests less than $1 \mathrm{~mm}$ ) and the requested accuracy was better than $0.2 \mathrm{~mm}$;

iv. The timing of the load tests: the bridge was closed to traffic for two days and in this period all the scheduled test had to be accomplished;

v. Stability and accessibility of the are under the bridge: due to the river stream, the area under the bridge is not easily accessible for the installation of reference points.

Due to this set of constraints, a geometric levelling was selected as the most suitable strategy for displacements measurement. Indeed, this allows the measurements of vertical displacements with an accuracy better than $0.2 \mathrm{~mm}$ without the need of installation of stable points in under the bridge (unlike LVDT). Also, due to the higher number of points to be measured (on both faces of the bridge) and the tight scheduling of the tests, a GPS and an RTS approach would need a longer acquisition time to obtain accuracies comparable with the ones achievable with geometric levelling. To measure vertical displacements a set of 47 benchmarks were fixed to the bridge road slab so that they have the same movements of the slab under loading. A geometric levelling network was then established to monitor vertical movements. The design of the network was carried out to maximize redundancy and create a set of closed loops. An optical level Zeiss Nil and a set of six levelling rods were employed to determine the deformation of the bridge. The instrument is equipped with a compensator, and it creates a horizontal line of sight; levelling rods must have regular graduation to obtain the scale of the levelled differences. According to the basic principle of levelling, the difference between the two readings is the elevation difference between the two benchmarks. The process is repeated to obtain the height difference between backsight and foresight points.. The displacement between points can be finally computed by measuring their difference of height in different epochs, e.g., before the test and during the bridge loading, with a simple difference of coordinates. Absolute displacements are determined by using as reference a benchmark located in a stable position, i.e., a position not affected by displacements during the loading test. In this case, a benchmark out of the bridge area was used as a reference. During the measurement, an optical level with the parallel plate glass micrometres gave the opportunity to improve reading precision. Rods with $5 \mathrm{~mm}$ graduations were employed, for which the collimation of the nearest reading with an adjustment screw is directly connected to the displacement measured by a micrometre. This provides readings with a precision of $\pm 0.05 \mathrm{~mm}$, that are then estimated to $\pm 0.005 \mathrm{~mm}$ by the operator. The measurements are then adjusted using least squares.

The following schema was adopted for the definition of the displacements:

i. Epoch-0: before the loading of the bridge an epoch-0 measurement was carried out, and it was considered as a reference for the computation of displacements

ii. $\quad$ Epoch-i: for each loading test (either type A or B) an epoch-i measurement was carried out starting from the benchmark considered as a reference out of the bridge area

iii. Epoch-unload: after the loading, a final epoch of measurement was carried out to verify if residual displacements remain in the structure due to the loading test. 
As a result of the monitoring for each test, a set of diagrams of the displacements is obtained that needs to be integrated into the

bridge BIM. Figure 2 shows an example of the vertical displacements obtained. The numerical value is not reported.

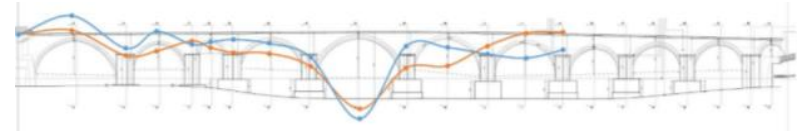

a.

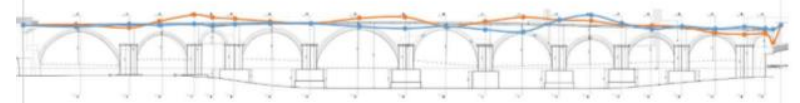

b.

Figure 3. vertical displacements during load testing: during type B test (a), during the unload epoch (b).

\section{BIM GENERATION BASED ON NOVEL GRADES OF GENERATION (GOG)}

Azzone Visconti bridge required different levels of detail (LOD) and geometry for the generation of an 'informative' model able to share different types of data such as levellingmonitoring data, materials, as-found drawings, historical reports and computing. The primary goal was to improve the information flow during the survey and analysis process.

Thanks to an accurate 3D survey, it was possible to collect different data sources such as point clouds from laser scanning and digital photogrammetry (primary data sources) and geometric, material-analysis and historical reports (secondary data sources).

Point cloud data led to intercept all the structural uniqueness of every single component such as vaults, piers, wing walls, foundations (parts out of rivers), road surface and its handrails (Fig. 3). Secondary data sources instead allowed in-depth analysis is showing the infrastructure's conservation status.

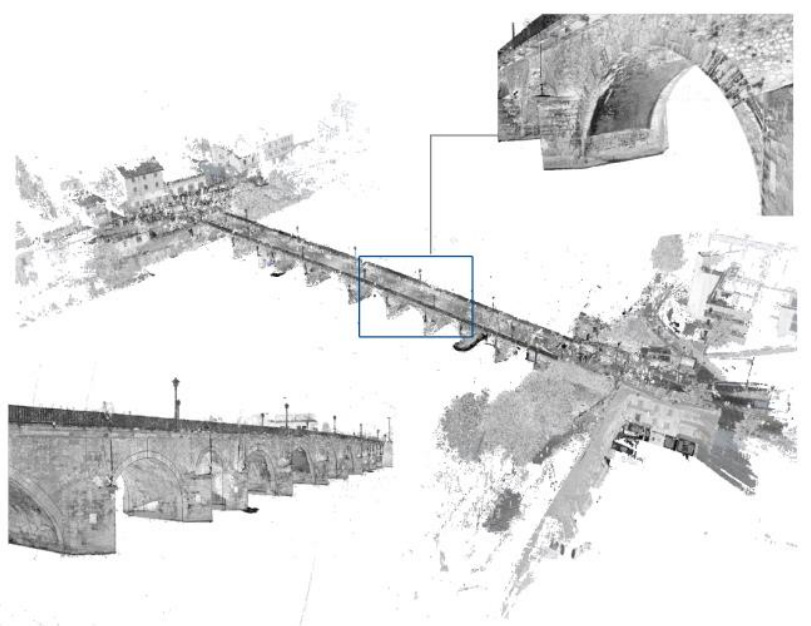

Figure 4. Azzone Visconti bridge's point clouds o and its geometric irregularities.

The generative process required the application of novel grades of generation (GOG) (Banfi 2017) for almost the entire medieval infrastructure with the aim of intercepting even the smallest geometric anomalies from the 3D survey.

The accuracy and precision obtained from generative modelling for every single vault of the bridge also made it possible to geometrically identify every single stone that makes up the 22 bridge's arches (two for each barrel vaults) and the holes left by the supporting structures for the construction of the bridge.

The research objectives were

- to automate the creation of two-dimensional drawings which had to consider all the out-lead of the bridge both of the north and the southern façade to facilitate the decision-making process for the bridge safeguard,

- to associate new types of data to the BIM model, such as the results of levelling (under load and without loading), decay analysis and historical reports, encouraging the sharing of results among the various experts involved in the process,

to share information and results via the 3D cloud for archiving and visualising structural health monitoring (SHM) data.

The generative process of the BIM model has made it possible to maximise one of the main tools of BIM software such as Autodesk Revit and Graphisoft Archicad: the automatic extraction of drawings from the BIM model.

In particular, GOG9 and 10 provide for (as a first requirement) the extraction of geometric primitives from point clouds. Thanks to the flexibility of these two Scan-to-bim modelling requirements, it was decided to create an ultra-detailed model immediately and then, in a second phase, to generate the 2D CAD drawings (cross sections, elevation and plans) useful for structural analyses.

Thanks to the high LOD of HBIM models, it was possible to benefit from the internal functions of Autodesk Revit and obtain a large number of vertical sections passing through both the pliers and the arches in order to show the asymmetries present in/between the north and south front (Fig. 4).

Every single barrel vault was characterised by irregularities along the entire intrados of the bridge. For this reason, it was decided to make explicit in this case the structural irregularities of the bridge through 22 cross sections.

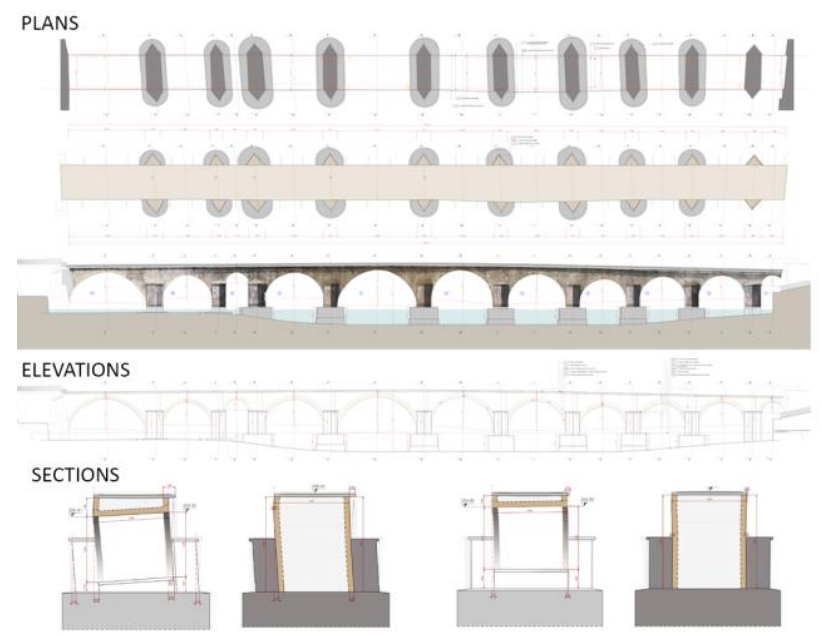

Figure 5. Azzone Visconti bridge's 2D CAD drawings from HBIM model.

In this specific case, the drawings were more useful than the BIM itself from a structural point of view. Thanks to the discontinuities intercepted in the bridge, subsequent structural analyses were carried out with the aim of demonstrating the 
stability of the bridge under load and without load (Martinelli et al. 2018).

Once the second objective was reached, it was possible to generate new $3 \mathrm{D}$ objects corresponding to the points measured by levelling.

This new technology allowed the surveyors to increase the sharing of the results of structural health monitoring (SHM). Accordingly, to partially obviate BIM gaps (only BIM experts can read the linked data), a solution has been proposed to favour the adoption of BIM and its methods of sharing through new levels of interoperability.

For this reason, for the case study of the bridge, it was decided to implement specific information parameters for each single BIM object created with the twofold objective (Fig. 5).:

- $\quad$ To describe the bridge in detail, also from a typological and not only morphological point of view

-

To create a storage system able to accommodate reports, structural analyses, historical documentation, 2D drawings and so on.
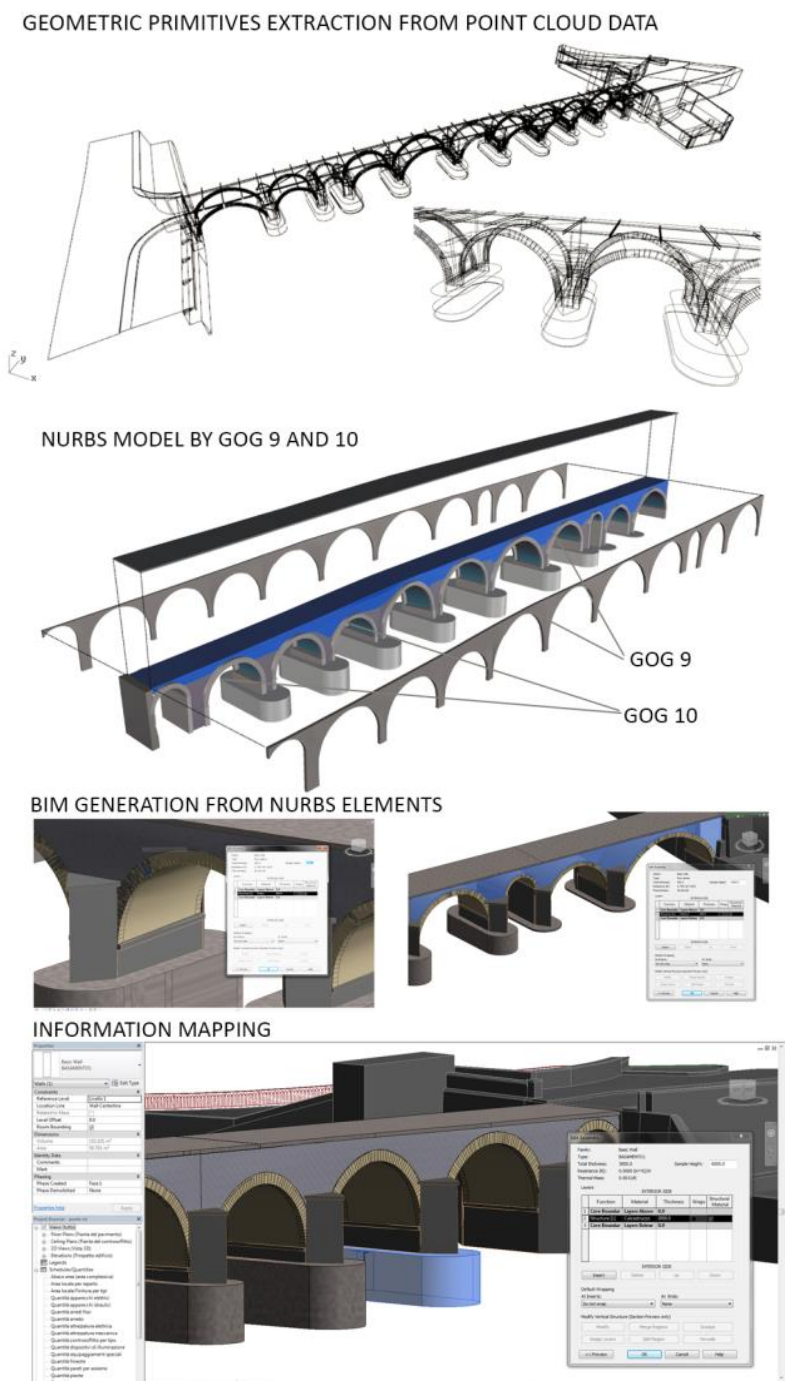

Figure 6. Azzone Visconti bridge's BIM generative process.

The generation of HBIM for a medieval infrastructure and the development of a cloud system able to share the results of the levelling led to a real repository for SHM. The information mapping of the BIM model has been enabled once 'new survey objects' have been created within the BIM project. As we well know, when we talk about the BIM, we consider the value of M (Modeling) and its strategic impact on the level of information (LOI) of the all BIM project. In fact thanks to BIM functions based on the automatic extraction of parametric value, it has been possible to connect different type of data such as levelling reports and material analysis.

These logics allow the establishment of smart relationships between model, information and survey reports, supporting the information sharing during the process (Fig. 6).

The main advantage of this system was to achieve a holistic approach based on a detailed scan-to-BIM model with a shared logic, favouring the reading of different type of data also for non-experts BIM users. The growing need to share a large amount of information, in turn, characterised by different digital formats, required the development of a digital repository able to connect all the experts involved in the process. The experience accumulated in the BIM generation and model sharing has allowed the setting of further steps for the creation of a digital hub where all the professionals could upload and share their work, results and analysis

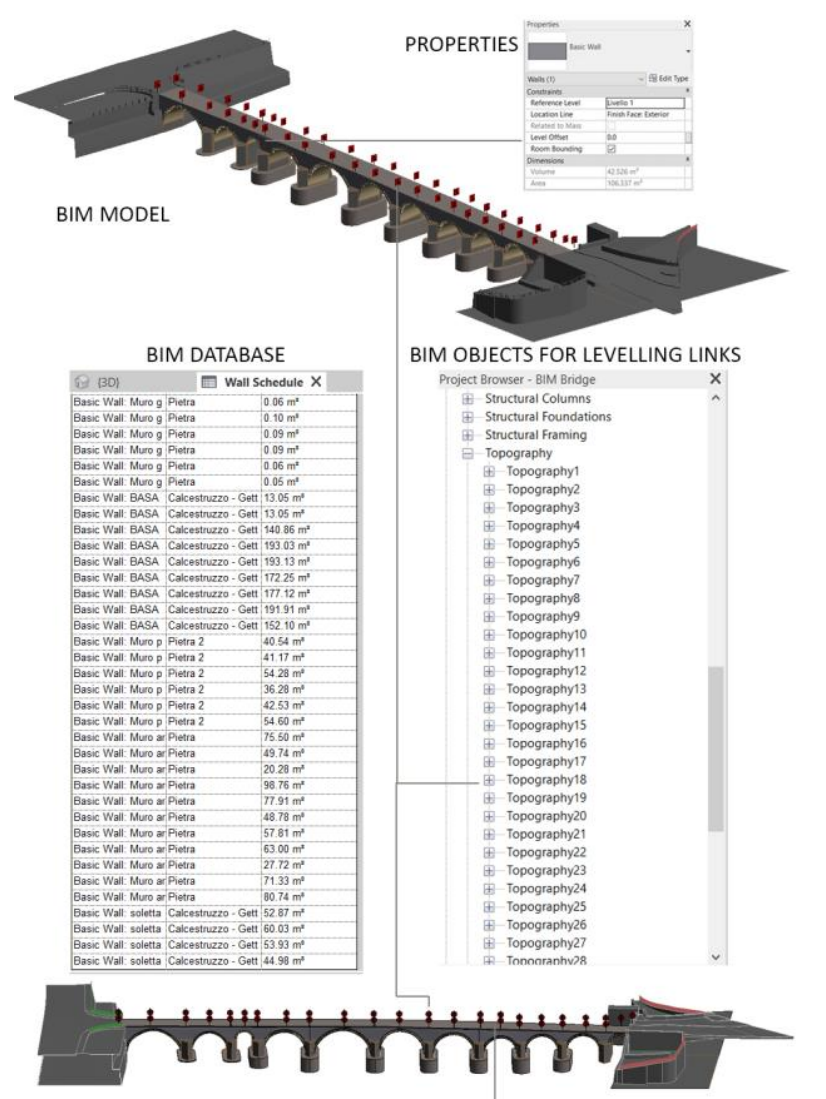

LEVELLING REPORTS (RECORDS VALUE)
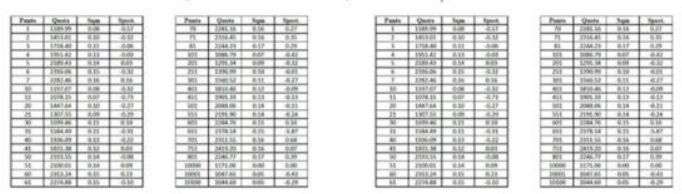

Figure 7. Azzone Visconti bridge's BIM linked to new 'levelling BIM objects'

Thanks to a shared logic, different types of files have been shared in the cloud, thus avoiding lengthy updating procedures between surveyors, engineers, architects and restorers. This 
shared logic was supported by the Autodesk A360 cloud which allows updates and modifies for any type of file from simple pdf to more advanced files such as dwf, dwxf, nwc which allow both the three-dimensional view of the model and the reading of information previously mappend within the BIM. The proper generation of accurate 3D Objects such as stone, intrados of arches, sprinter, springing lines, deck, floor beams and stringers has allowed the integration and sharing of non-graphic information in the cloud.

The main advantage of this system was to be able to share complex models even to experts with a low level of knowledge of these new BIM technologies. In fact, the visualization and interaction with the model were flexible and fast at the same time (Fig. 7).

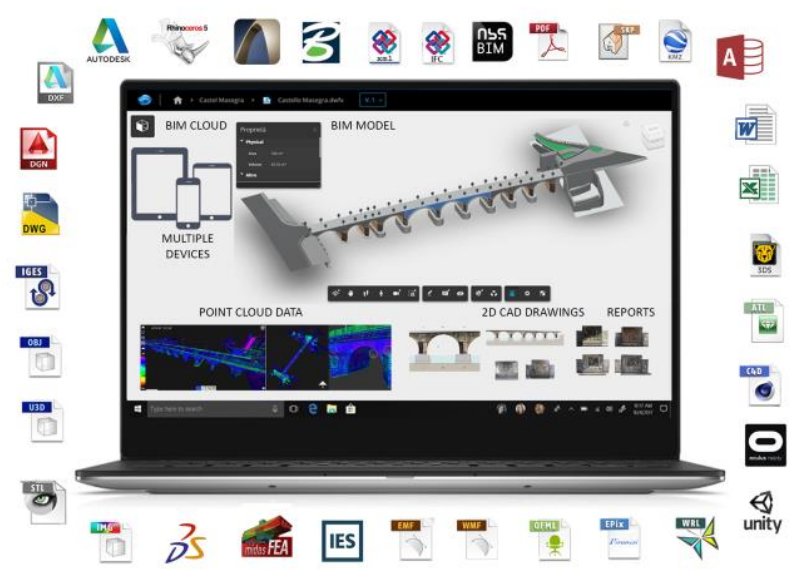

Figure 8. Azzone Visconti bridge's BIM cloud.

\section{CONCLUSIONS}

This paper presented an integration between BIM management and information coming from load testing. The main point addressed in this paper is the generation of a smooth workflow for data sharing between different actors involved in the management of a bridge (e.g., public administration, surveyors, structural engineers, etc.). The availability of a unique repository for data coming from different sources is one of the main advantages in adopting the BIM paradigm for infrastructure management. However, a deeper integration with cartographic data sources, like Geographical information Systems (GIS), is still needed to fruitfully take advantage of the simulation and analytical tools available in GIS domain. An important aspect faced in this paper is also the need to overcame commercial software solutions. Indeed, the adoption of a unique platform, even if may solve some interoperability issues, can be a barrier for the adoption of the BIM paradigm to different specialists each one using specific solutions customized for its needs. The development of a cloud based solutions tries to overcome the dependence to specific software platform simplifying the adoption of informative models to different user communities.

\section{ACKNOWLEDGEMENTS}

The authors are indebted to the Municipality of Lecco and "Consorzio fiume Adda" for the precious historical and technical documents acquired with their help and Arch. Chiara Rostagno (official of Ministry of Cultural Heritage and
Tourism, Superintendent of Fine Arts and Landscape) for the stimulating discussions and the appreciated suggestions on the historical material provided.

Authors wold like to thank Prof. Marco Di Prisco, scientific coordinator of the collaboration between Politecnico di Milano (Polo Territoriale di Lecco) and the Municipality of Lecco (Italy) for the investigation of the bearing capacity of Azzone Visconti bridge.

\section{REFERENCES}

Agdas, D., Rice, J. A., Martinez, J. R., Lasa, I. R., 2015. Comparison of visual inspection and structural-health monitoring as bridge condition assessment methods. Journal of Performance of Constructed Facilities, 30(3), 04015049.

Banfi, F. (2016, October). Building information modelling-a novel parametric modeling approach based on $3 \mathrm{~d}$ surveys of historic architecture. In Euro-Mediterranean Conference (pp. 116-127). Springer, Cham.

Banfi, F. (2017). BIM ORIENTATION: GRADES OF GENERATION AND INFORMATION FOR DIFFERENT TYPE OF ANALYSIS AND MANAGEMENT PROCESS. International Archives of the Photogrammetry, Remote Sensing and Spatial Information Sciences, 42(2/W5).

Barazzetti, L., Banfi, F., Brumana, R., Roncoroni, F., Previtali, M., 2016. BIM from laser scans... not just for buildings: NURBS-based parametric modeling of a medieval bridge. In XXIII ISPRS Congress, Commission V (pp. 51-56).

Brownjohn, J. M., Koo, K. Y., Scullion, A., List, D., 2015. Operational deformations in long-span bridges. Structure and Infrastructure Engineering, 11(4), 556-574.

Corongiu, M., Tucci, G., Santoro, E., Kourounioti, O., 2018. DATA INTEGRATION OF DIFFERENT DOMAINS IN GEOINFORMATION MANAGEMENT: A RAILWAY INFRASTRUCTURE CASE STUDY. International Archives of the Photogrammetry, Remote Sensing \& Spatial Information Sciences, 42(4).

Jeong, S., Hou, R., Lynch, J. P., Sohn, H., Law, K. H., 2017. An information modeling framework for bridge monitoring. Advances in engineering software, 114, 11-31.

Korumaz, M., Betti, M., Conti, A., Tucci, G., Bartoli, G., Bonora, V., Korumaz, A.G., Fiorini, L., 2017. An integrated Terrestrial Laser Scanner (TLS), Deviation Analysis (DA) and Finite Element (FE) approach for health assessment of historical structures. A minaret case study. Engineering Structures, 153, 224-238.

Hu, Z. Z., Zhang, X. Y., Wang, H. W., Kassem, M., 2016. Improving interoperability between architectural and structural design models: An industry foundation classes-based approach with web-based tools. Automation in Construction, 66, 29-42.

Hester, D., Brownjohn, J., Bocian, M., Xu, Y., 2017. Low cost bridge load test: calculating bridge displacement from acceleration for load assessment calculations. Engineering Structures, 143, 358-374.

Lin, J. R., Zhang, J. P., Zhang, X. Y., Hu, Z. Z., 2019. Automating closed-loop structural safety management for 
bridge construction through multisource data integration. Advances in Engineering Software, 128, 152-168.

Moschas, F., and Stiros, S. C., 2014. Three-dimensional dynamic deflections and natural frequencies of a stiff footbridge based on measurements of collocated sensors. Structural Control and Health Monitoring, 21(1), 23-42.

Noel, A. B., Abdaoui, A., Elfouly, T., Ahmed, M. H., Badawy, A., Shehata, M. S., 2017. Structural health monitoring using wireless sensor networks: A comprehensive survey. IEEE Communications Surveys \& Tutorials, 19(3), 1403-1423.

Okiemute, E. S., Fatai, O. O., 2018. Monitoring and Analysis of Vertical Deformation of Palm House Benin City Using Digital Level. International Journal of Advances in Scientific Research and Engineering, 4.

Scheer, J., 2011. Failed bridges: case studies, causes and consequences. John Wiley \& Sons.

Sekiya, H., Kimura, K., Miki, C., 2016. Technique for determining bridge displacement response using MEMS accelerometers. Sensors, 16(2), 257.

Tang, X., Roberts, G. W., Li, X., Hancock, C. M., 2017. Realtime kinematic PPP GPS for structure monitoring applied on the Severn Suspension Bridge, UK. Advances in Space Research, 60(5), 925-937.

Tucci, G., Bonora, V., Guardini, N., 2013. ANALYSIS OF THE FACTORS AFFECTING 3D MODELS RESOLUTION. APPLICATION TO THE RECORDING OF VAULTS IN SANGALLO'S HOUSE. ISPRS Annals of Photogrammetry, Remote Sensing and Spatial Information Sciences, 1(1), 307312 .

Volk, R., Stengel, J., \& Schultmann, F. (2014). Building Information Modeling (BIM) for existing buildings-Literature review and future needs. Automation in construction, 38, 109127.

Xi, R., Jiang, W., Meng, X., Chen, H., Chen, Q., 2018. Bridge monitoring using BDS-RTK and GPS-RTK techniques. Measurement, 120, 128-139.

Zhou, H. F., Ni, Y. Q., Ko, J. M., 2006. Analysis of structural health monitoring data from the suspension Jiangyin Bridge. In Proceeding of the 3rd European workshop on structural health monitoring (pp. 364-371). 